\title{
The New Editor-in-Chief of Molecular Neurobiology
}

Published online: 7 April 2020

(C) Springer Science+Business Media, LLC, part of Springer Nature 2020

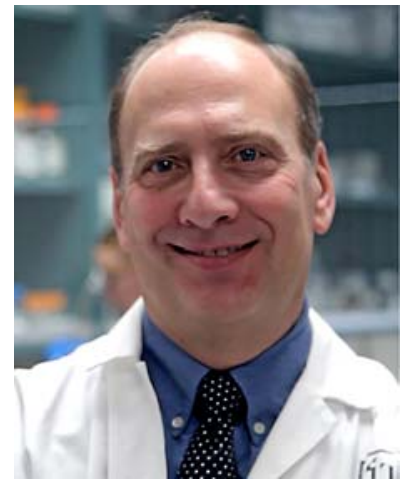

\section{Springer Nature}

Springer Nature is pleased to announce that Benedict C. Albensi, PhD, BCMAS, CRQM, has been named Editorin-Chief of Molecular Neurobiology. Dr. Albensi is Full Professor \& Manitoba Dementia Research Chair, Max
Rady College of Medicine, University of Manitoba and Principal Investigator, Everett Endowment Fund Chair (Alzheimer's research), St. Boniface Hospital Research. Dr. Albensi shares our vision to ensure that authors who submit to MOLN have a high-quality experience that further raises the reputation of the journal.

Dr. Albensi will be focusing on increasing the impact of the journal by focusing on special issues exploring timely topics such as sex and gender-based differences in molecular neurobiology. In addition, increased focus on social media activity will strengthen the reach and visibility that the journal has in the scientific community. He is also eager to increase the engagement and involvement of the Editorial Advisory Board. To that end, Dr. Albensi and Springer Nature will host an annual meeting for the Board either in person or via webinar and new measures will be implemented to gather feedback from Board members on a more consistent basis.

We look forward to the continued success of the journal under Dr. Albensi's leadership. 